\title{
Determinants of late initiation for antenatal care follow up: the case of northern Ethiopian pregnant women
}

\author{
Fitsum Wolde ${ }^{1}$, Zerfu Mulaw², Tibeb Zena ${ }^{2}$, Belete Biadgo ${ }^{3}$ and Miteku Andualem Limenih ${ }^{2 *}$
}

\begin{abstract}
Objective: Early antenatal care follow-up is the main strategy of preventing pregnancy related adverse outcomes; in which World Health Organization recommends first antenatal care visit should be offered within the first trimester. However, Low utilization and late booking is the predominant problem in most developing countries including Ethiopia. This study aimed to determine the prevalence of late initiation for antenatal care follow-up and associated factors among pregnant women. Institutional based cross-sectional study was conducted among 423 pregnant mothers using systematic sampling technique. Multivariable logistic regression analysis was performed at the level of significance of $p$-value $\leq 0.05$.

Results: The findings showed $59.4 \%$ of pregnant women started their first visit after first trimester. Having age $\geq 25$ years ( $A O R=1.62, \mathrm{Cl} 1.1,2.49$ ), recognition of pregnancy by missed period ( $\mathrm{AOR}=2.54 \mathrm{Cl} 1.63,3.96$ ), pregnant mother who were not advised to start antenatal-care $(A O R=3.36, \mathrm{Cl} 1.74,6.5)$ and primary educational level $(A O R=2.22, C l 1.16,4.25)$ were found to be significantly associated with late initiation for antenatal care. The prevalence of late antenatal care follow-up is high. Multidisciplinary approaches to keep empowering women through education are recommended for early initiation of antenatal care.
\end{abstract}

Keywords: Antenatal care, Ethiopia, Late initiation of antenatal care

\section{Introduction}

Sub-Saharan Africa including Ethiopia had the highest maternal mortality ratio of 510 and 420 per 100,000 live births respectively [1]. To alleviate this problem, antenatal care a key entry point. It's a care given to pregnant mother from the time of conception until the beginning of labor to avoid and minimize possible risks of morbidity and mortality $[2,3]$. Hence, World Health Organization recommends that a pregnant woman should have at least four antenatal care visits, the first of which should be on the first trimester [2].

Worldwide there is a big discrepancy in the prevalence of late ANC follow up among pregnant mothers, ranging from 27.5 to $88 \%$ in developed and developing countries

\footnotetext{
*Correspondence: mitekuandualem2017@gmail.com

2 Department of Midwifery, College of Medicine and Health Science, University of Gondar, P.O. Box 196, Gondar, Ethiopia

Full list of author information is available at the end of the article
}

respectively $[4,5]$. Low prenatal coverage, few visits, and delayed initiation of antenatal follow up are the predominant problems throughout SSA including Ethiopia resulting in failure of accomplishment of the WHO recommendation [2].

The minimum ANC visits recommended by WHO was possible only for less than about a third of the pregnant women in some SSA countries like Niger (15\%), Ethiopia (19\%), Chad (23\%), Burundi (33\%), Mali and Rwanda (35\%) [6].

Despite ANC is provided free of charge and there is increased accessibility; low utilization and late booking is still a major problem [7, 8]. According to Ethiopian Demographic Health Survey 2014, only $17.5 \%$ mothers start ANC early as per the recommendation [9].

Prevalence of late booking vary from country to country, not only because of its real difference in occurrence but also due to differences in definitions of late booking $[3,6]$. According to researches, maternal age, maternal 
education, husband's education, income, women's employment, type of pregnancy, counseling on early initiation of ANC, Previous ANC service utilization, parity and means of pregnancy recognition are contributing factors $[5,10-24]$.

However, the determinants of late initiation for ANC are not the same across different cultures, socio economic status and access to institution within a society. Thus assessing the factors of late initiation of ANC follow up in different set up is important to improve maternal health services. Therefore, this study aimed at determining the prevalence of late ANC initiation and factors associated with it among pregnant women attending antenatal clinic in governmental health institutions at Debremarkos town, Ethiopia.

\section{Theoretical frame work}

Maternal age, marital status, occupation, income, educational status and paternal education were the predisposing factors for late initiation of antenatal care follow-up whereas; previous antenatal care utilization, family size, means of pregnancy recognition and previous pregnancy complication were enabling factors and parity, type of pregnancy and knowledge on antenatal care visit were the need factors.

\section{Main text}

\section{Study area and period}

The study was conducted at Debremarkos governmental health institutions from March 1 to June 1, 2016. The total population of the town was 101,582 [28]. There are four governmental health institutions (three health centers and one referral hospital). To provide the service there were $1 \mathrm{BSc}$, 14 diploma Midwives and 8 diploma Nurses.

\section{Study design}

Institutional based cross sectional study design was employed.

\section{Study population}

All pregnant women attending ANC in Debremarkos governmental health institutions during the study period were included.

\section{Sample size determination}

A total of 423 samples were calculated using single population proportion formula by considering, 95\% confidence level, $5 \%$ margin of error and the prevalence of late initiation for ANC follow up 52.6\% [20] and considering $10 \%$ of possible non response rate.

\section{Sampling procedure}

To select participants, systematic random sampling techniques were employed. The total sample size was proportionally allocated for three health centers and one referral hospital based on their ANC loads. By considering; $\mathrm{N}$ (total pregnant woman who came for first ANC visit in previous 3 months in 4 health institutions $=850), \mathrm{n}$ (calculated sample size $=423$ ) and k-interval $(K=N / n,=850 / 423=2)$, the first client was selected by lottery method among the first two ANC service users.

$$
\mathrm{n}_{\mathrm{h}}=\mathrm{N}_{\mathrm{h}} * \mathrm{n} / \mathrm{N}
$$

$\left[\mathrm{n}_{\mathrm{h}}=\right.$ sample size allocated to each health institution, $\mathrm{N}_{\mathrm{h}}=$ number of ANC clients in a health institution in previous 3 months (Debremarkos referral hospital $=280$, Wuseta health center $=220$, Hidase Health center $=210$ and Debremarkos Health center $=140), \mathrm{N}=$ cumulated number of ANC clients in all health institutions in previous 3 months (850), $\mathrm{n}=$ total sample size (423)] resulting in final sample size (Debremarkos referral hospital $=139$, Hidase health center $=105$, Wuseta Health center $=109$ and Debremarkos health center $=70$ ).

\section{Construction of variables}

Late initiation for ANC visit was the outcome variable where as the independent variables were constructed in demographic and socio-economic variables (maternal age, marital status, education, occupation, income, family size, paternal educational status), obstetric related factors (parity, means of pregnancy recognition, type of pregnancy, previous history of complication), service related variables (previous utilization of ANC service) and client related variables (advice from others, Knowledge about ANC).

\section{Data collection instruments and techniques}

Data was collected by face to face interview using structured and pre-tested questionnaire. The questionnaire was first prepared in English and translated to local language for interview. The data was collected by eight diploma Midwives.

\section{Data processing and analysis}

Data were entered into EPI Info version 7.1.2.0 and exported to SPSS version 20 software for analysis. Variables having a $p$-value of $\leq 0.20$ in bivariate analysis were entered into multiple logistic regressions. Finally variables with a p-value of $\leq 0.05$ were considered as statistically significant. Moreover, multi-colinearity was checked 
using the variance inflation factor, and it shows no colinearity effect.

\section{Socio-demographic characteristics of the participants}

A total of 423 mothers who came for ANC follow up in Debremarkos governmental health institutions were interviewed with a response rate of $98.35 \%$. The median age was 25 years. Majority of them, 405 (97.4\%) were Orthodox Christians. Amhara ethnic group holds 415 (99.8\%) (Table 1).

\section{Obstetric history related characteristics of the study subjects $(n=416)$}

Two hundred forty-nine (59.9\%) of pregnant women were multigravida; out of this, $179(71.9 \%)$ had no history of complication during their last pregnancy. 168 (40.4\%), 167 (40.1\%) and 81 (19.5\%) were primiparous, nulliparous and multiparous respectively.

\section{Knowledge of participants about ANC service}

Three hundred eighty-nine (93.5\%), 16 (3.9\%) and 11 (2.6\%) participants rated the importance of ANC follow up as highly, medium and less important for both the mother and fetus respectively. Of the respondents, 187 (45\%), 188 (45.1\%) and 41 (9.9\%) reported that the right time to start ANC follow up is in the first 3 months of pregnancy, after 3 months of pregnancy and they don't know the right time of initiation respectively. Three hundred nine (74.3\%) knows number of ANC visit should be $\geq 4$.

\section{Past history of ANC service utilization}

Among 249 (59.9\%) pregnant women who had a history of previous pregnancy, $69.9 \%$ of them had ANC follow up for the previous last pregnancy. Among these, $48.8 \%$ of them had their previous ANC visit at 12 weeks.

\section{Pregnant mother's commencement to ANC follow-up}

In this study, $59.4 \%$ of participants started their ANC follow up lately. Among the late comers for ANC follow up, $43.3 \%$ of them perceived that it is the right time to start, while other mentioned reasons are; previous experience (26.7\%), lack of time (14.2\%), unplanned pregnancy $(8.9 \%)$, because of sickness and unawareness of pregnancy $(6.5 \%)$ and negligence $(0.4 \%)$.

The timing of first ANC booking ranged from week 4 to 40; the median gestational age during the first antenatal care booking was 15 weeks (Fig. 1).

\section{Associated factors for late ANC follow up initiation}

Maternal age, means of pregnancy recognition, maternal educational status, advice to start visit were significant factors for late ANC follow up initiation. The odds
Table 1 Socio-demographic and economic characteristic of pregnant mother attending ANC service in Debre Markos governmental health institution, Ethiopia, 2016 $(n=416)$

\begin{tabular}{lc}
\hline Variables & Frequency (\%) \\
\hline Age & \\
$<25$ (young) & $180(43.3 \%)$ \\
$\geq 25$ & $236(56.7 \%)$ \\
Ethnicity & $415(99.8 \%)$ \\
Amhara & $1(0.2 \%)$ \\
Tigrie & \\
Marital status & $396(95.2 \%)$ \\
Married & $11(2.6 \%)$ \\
Cohabitation & $9(2.2 \%)$ \\
Divorced/widowed & \\
Religion & $405(97.4 \%)$ \\
Orthodox & $6(1.4 \%)$ \\
Muslim & $5(1.2 \%)$ \\
Protestant & \\
Educational status & $103(24.8 \%)$ \\
No formal education & $82(19.7 \%)$ \\
Primary [1-8] & $125(30 \%)$ \\
Secondary [9, 10] and certificate & $106(25.5 \%)$ \\
College diploma and above & \\
Employment status & $254(61.1 \%)$ \\
Employed & $162(38.9 \%)$ \\
Not employed & \\
Father education & $62(14.9)$ \\
No formal education & $78(18.8)$ \\
Primary [1-8] & $119(28.6)$ \\
Secondary [9, 10] and certificate & $157(37.7 \%)$ \\
College diploma and above & \\
Family monthly income & $50(12 \%)$ \\
$<$ US\$37 & $284(68.3 \%)$ \\
\$US37-US\$148 & $82(19.7 \%)$ \\
$>$ US\$148 & \\
Family size & $286(68.8)$ \\
$\leq 3$ & $130(31.2 \%)$ \\
$>3$ & \\
\hline & \\
\hline &
\end{tabular}

of pregnant mother aged 25 years and above were 1.62 times more likely to have a late initiation for ANC follow up than their counter parts $(\mathrm{AOR}=1.62$, CI 1.049, 2.49). Those pregnant mothers who recognized their pregnancies by missed period were 2.54 times more likely to have late ANC initiation than those recognized their pregnancy by urine test $(\mathrm{AOR}=2.54 \mathrm{CI} 1.63$, 3.96). Pregnant mothers who were not advised to start ANC were 3.36 times more likely to come late for ANC follow up than those who received advice $(\mathrm{AOR}=3.36$, CI 1.74, 6.5). Mothers who attended primary education were 2.22 times more likely to have late ANC follow-up 


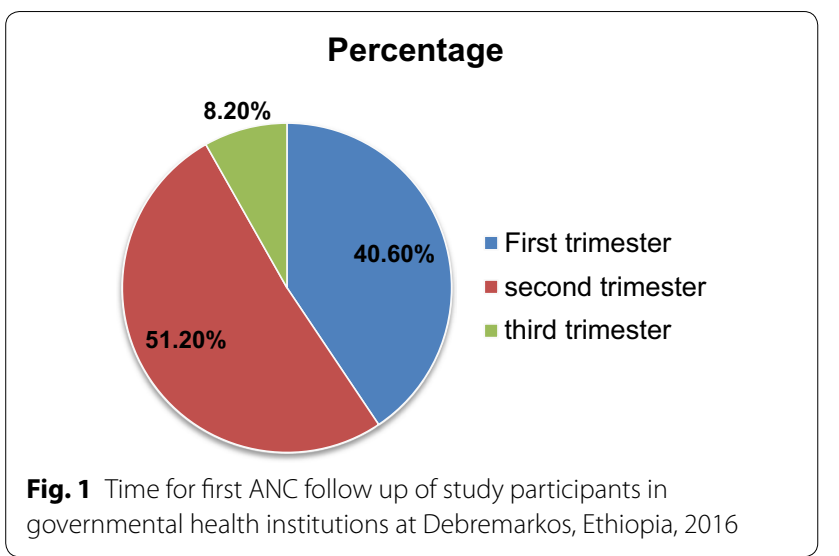

initiation than those mothers had diploma and above $(\mathrm{AOR}=2.22$, CI 1.16, 4.25) (Table 2).

\section{Discussion}

This study revealed that $59.4 \%$ of pregnant women started their ANC follow up after 12 weeks of gestation, which is late ANC follow up initiation. This finding is in line with a study done in Addis Ababa 59.8\% [11].

The finding of this study was encouraging as compared to the studies conducted in Uganda (83\%), Nigeria (82\%) and Thailand $(73.8 \%)[8,25,26]$. However, it is remarkably higher than the study done in Vietnam in which late ANC follow up were $27.5 \%$ [4]. This might be due to the difference in socioeconomic status and health service coverage. The difference in prevalence across studies might be socio demographic features of the study participants, media of information among health care givers, knowledge of mothers on importance of early ANC follow up, the time gap between the study periods and the difference in data collection methods $[4,8]$.

Pregnant mother aged $\geq 25$ were 1.62 times more likely to book late than those pregnant women age less or equal to 25 years. This result is supported by the studies done in Nigeria, Kembata and Gondar [16-18]. This might be due to women in the older age group are more likely to have many children to care and many of the older pregnant women's might have ingrained cultural biases against formal health care [16].

On the contrary, studies done in rural Adigrat, Uganda and Vietnam showed that teenagers were more likely to start ANC lately than adults [27-29]. This observed difference might be due to the difference in the study population, in which all studies included rural population. Its fact that rural setup can generally be expected to have less knowledge and experiences about ANC.

Pregnancies, recognized by missed periods were 2.54 times more likely to initiate ANC lately than those who recognized by a urine test. This finding is consistent with the study done in Gondar [18]. This might be due to the reason that mothers having irregular menstrual cycle are not curious about the missed period. This is supported by the study done in South African women that delayed recognition of pregnancy and late ANC initiation has also been reported [30].

Those pregnant mothers who were not counseled to start ANC follow-up were 3.36 times more likely to have late initiation of ANC follow up than those who received counseling. This result is in line with the study done in Adigrat and Nigeria, in which those pregnant mothers who were advised by health workers started their ANC follow up timely [10, 25].

It might be due to the fact that provision of appropriate information changes health seeking behavior of women and motivate them to visit a well-organized health institution timely [5].

Respondents who were in primary educational status were 2.22 times more likely to initiate ANC lately than those having collage diploma and above. This result is supported by similar other study in South Sudan [31]. The possible explanation might be, as the level of educational status increases, the pregnant women would more likely to give value for the benefit of timely initiation. Furthermore, pregnant women who had college diploma and above have information on benefits of timely booking for ANC [5].

\section{Conclusions and recommendation}

Late initiation of ANC is a high problem in the study area. Maternal age $\geq 25$, means of pregnancy recognition, lack of advice, and being at primary educational status were determinant factors for late ANC initiation. Keeping strengthening the expansion of education on ANC, promoting health education, creating awareness, empowering women and giving appropriate advice on pregnancy and timely ANC follow-up would improve late initiation for antenatal care. 
Table 2 Logistic regression showing factors on late ANC follow up initiation among mothers who came for ANC clinic in Debremarkos governmental health institution, Ethiopia, $2016(n=416)$

\begin{tabular}{|c|c|c|c|c|}
\hline \multirow[t]{2}{*}{ Variable } & \multicolumn{2}{|c|}{ Late initiation } & \multicolumn{2}{|l|}{ OR $(95 \% \mathrm{Cl})$} \\
\hline & Yes & No & COR & AOR \\
\hline \multicolumn{5}{|l|}{ Maternal age } \\
\hline$<25$ (young) & 97 (53.9\%) & $83(46 \%)$ & 1 & 1 \\
\hline$\geq 25$ & $150(63.6 \%)$ & $86(36.4 \%)$ & $1.49(1.005,2.22)$ & $1.62(1.049,2.49)$ \\
\hline \multicolumn{5}{|l|}{ Maternal educational status } \\
\hline No formal education & $60(58.3 \%)$ & $43(41.7 \%)$ & $1.62(0.94,2.8)$ & a \\
\hline Primary (1-8) & $58(70.7 \%)$ & $24(29.3 \%)$ & $2.8(1.53,5.2)$ & $2.22(1.16,4.25)$ \\
\hline Secondary and certificate & $80(64 \%)$ & $45(36 \%)$ & $2.1(1.23,3,5)$ & a \\
\hline College diploma and above & 49 (46.2\%) & $57(53.8 \%)$ & 1 & 1 \\
\hline \multicolumn{5}{|l|}{ Employment status } \\
\hline Not employed & $104(64.2 \%)$ & $58(35.8 \%)$ & $1.39(0.93,2.1)$ & a \\
\hline Employed & $143(56.3 \%)$ & $111(43.7 \%)$ & 1 & 1 \\
\hline \multicolumn{5}{|l|}{ Knowledge on ANC } \\
\hline Inadequate knowledge & $22(73.3 \%)$ & $8(26.7 \%)$ & 1 & 1 \\
\hline Adequate knowledge & $225(58.3 \%)$ & $161(41.7 \%)$ & $1.97(0.9,4.5)$ & a \\
\hline \multicolumn{5}{|l|}{ Family size } \\
\hline$>3$ & $70(53.8 \%)$ & $60(46.2 \%)$ & $0.72(0.5,1.1)$ & a \\
\hline$\leq 3$ & $177(61.9 \%)$ & $109(38.1 \%)$ & 1 & 1 \\
\hline \multicolumn{5}{|l|}{ Income } \\
\hline$<1000(\mathrm{Q} 1)$ & $30(60 \%)$ & $20(40 \%)$ & $1.65(0.8,3.4)$ & a \\
\hline $1000-4000$ & $178(62.7)$ & $106(37.3 \%)$ & $1.85(1.13,3.04)$ & a \\
\hline > $4000(\mathrm{Q} 3)$ & $39(47.6 \%)$ & 43 (52.4\%) & 1 & 1 \\
\hline \multicolumn{5}{|l|}{ Pregnancy recognition } \\
\hline By missed period & $164(69.5 \%)$ & $72(30.5 \%)$ & $2.7(1.8,3.98)$ & $2.54(1.63,3.96)$ \\
\hline By urine test & $83(46.1 \%)$ & 97 (53.9\%) & 1 & 1 \\
\hline \multicolumn{5}{|l|}{ Advise to start ANC visit } \\
\hline No & $53(79 \%)$ & $14(20.9 \%)$ & $3(1.62,5.66)$ & $3.36(1.74,6.5)$ \\
\hline Yes & $194(55.6 \%)$ & $155(44.4 \%)$ & 1 & 1 \\
\hline \multicolumn{5}{|l|}{ Type of pregnancy } \\
\hline Not planned & $40(71.4 \%)$ & $16(28.6 \%)$ & $1.85(0.9,3.4)$ & a \\
\hline Planned & $207(57.5 \%)$ & $153(42.5 \%)$ & 1 & 1 \\
\hline \multicolumn{5}{|l|}{ Paternal educational status } \\
\hline No formal education & $37(59.7 \%)$ & 25 (40.3\%) & $1.32(0.73,2.4)$ & a \\
\hline Primary (1-8) & $52(66.7 \%)$ & $26(33.3 \%)$ & $1.8(1,3.1)$ & a \\
\hline Secondary and certificate & $75(63 \%)$ & $44(37 \%)$ & $1.5(0.9,2.5)$ & a \\
\hline College diploma and above & $83(52.9 \%)$ & $74(47.1 \%)$ & 1 & 1 \\
\hline
\end{tabular}

The italicized value indicated that a statistically significant association at 95\% Confidence interval(Cl) that did not include 1 in the interval

$1=$ reference category

${ }^{a}$ Not significant in stepwise backward logistic regression. Hosmer and Lemanshow test for multivariable log reg. $=0.85$

\section{Limitations of the study}

Gestational age was determined based on women's report. This might have inaccuracies in the measurement of gestational age.

\section{Abbreviations}

ANC: antenatal care; AOR: adjusted odds ratio; $\mathrm{Cl}$ : confidence interval; $\mathrm{COR}$ : crude odds ratio; EDHS: Ethiopian Demographic and Health Survey; SPSS:
Statistical Package for Social Science; SSA: Sub-Saharan Africa; WHO: World Health Organization.

\section{Authors' contributions}

FW: initiated the idea, wrote the proposal, participated in designing the study, supervising data collection process, analyses the data and writing the manuscript. ZM, TZ, BB: contributed in the designing of the methodology, analysis of the data, add important intellectual content and final prepared the manuscript and approval of the manuscript to be published. MAL: involved in proposal writing, contributed in the designing of the methodology, analysis of the data, add important intellectual content and final prepared the 
manuscript and approval of the manuscript to be published. All authors read and approved the final manuscript.

\section{Author details}

${ }^{1}$ Department of Midwifery, College of Health Science, Arbaminch University, Arbaminch, Ethiopia. ${ }^{2}$ Department of Midwifery, College of Medicine and Health Science, University of Gondar, P.O. Box 196, Gondar, Ethiopia.

${ }^{3}$ Department of Clinical Chemistry, College of Medicine and Health Science, University of Gondar, P.O. Box 196, Gondar, Ethiopia.

\section{Acknowledgements}

The authors would like to pass their gratitude to the University of Gondar, study participants and Alicia Helion (Dr.) for language edition and technical comments.

\section{Competing interests}

The authors declare that they have no competing interests.

\section{Availability of data and materials}

When ethics statement was obtained from the district health office, we have agreed and signed not to publish the raw data retrieved from the data of pregnant women's. However, the datasets collected and analyzed for the current study is available from the corresponding author and can be obtained on a reasonable request.

\section{Consent for publication}

Not applicable.

\section{Ethics approval and consent to participate}

Ethical clearance was obtained from internal ethical review board of university of Gondar. Written informed consent was obtained from each study participants after verbal explanation to be involved in the study. Information was given regarding the right to refuse or withdraw from the interview. Personal identifiers were not included in the written questionnaires to ensure participants' confidentiality.

\section{Funding}

The authors did not receive any funding for this study.

\section{Publisher's Note}

Springer Nature remains neutral with regard to jurisdictional claims in published maps and institutional affiliations.

\section{Received: 22 October 2018 Accepted: 21 November 2018}

Published online: 27 November 2018

\section{References}

1. UNICEF. Trends in maternal mortality: 1990 to 2013. Washington: World Bank Publications; 2014.

2. Lincetto O, Mothebesoane-Anoh S, Gomez P, Munjanja S. Antenatal care. Opportunities for Africa's newborns: practical data, policy and programmatic support for newborn care in Africa. 2006. p. 80-90.

3. Abou-Zahr CL, Wardlaw TM. Antenatal care in developing countries: promises achievements and missed opportunities. An analysis of trends levels and differentials 1990-2001. 2003.

4. Le Nguyen TT, Deoisres W. Factors predicting timely initiation of antenatal care among pregnant women in Binh Dinh Province, Vietnam. J Nurs Sci Health. 2016;38(4):123-36.

5. Turyasiima M, Tugume R, Openy A, Ahairwomugisha E, Opio R, Ntunguka M, Mahulo N, Akera P, Odongo-Aginya E. Determinants of first antenatal care visit by pregnant women at community based education. East Afr Med J. 2014;91(9):317-22.

6. Berhan Y, Berhan A. Antenatal care as a means of increasing birth in the health facility and reducing maternal mortality: a systematic review. Ethiop J Health Sci. 2014;24:93-104.

7. WHO, World Bank. Trends in maternal mortality: 1990 to 2008. Geneva: $\mathrm{WHO} ; 2012$
8. Zegeye AM, Bitew BD, Koye DN. Prevalence and determinants of early antenatal care visit among pregnant women attending antenatal care in Debre Berhan Health Institutions. Central Ethiopia. Afr J Reprod Health. 2013;17(4):130-6.

9. Demographic E. Health survey report. Addis Ababa: Central Statistical Agency and ICF International; 2014.

10. Lerebo W, Kidanu A, Tsadik M. Outcome of late booking for antenatal care in Public Health Centers of Adigrat Town, Tigray, Ethiopia. Clin Mother Child Health. 2016.

11. Tariku A, Melkamu Y, Kebede Z. Previous utilization of service does not improve timely booking in antenatal care: cross-sectional study on timing of antenatal care booking at public health facilities in Addis Ababa. Ethiop J Health Dev. 2010. https://doi.org/10.4314/ejhd.v24i3.68390.

12. Gebremeskel F, Dibaba Y, Admassu B. Timing of first antenatal care attendance and associated factors among pregnant women in Arba Minch Town and Arba Minch District, Gamo Gofa Zone. South Ethiopia. J Environ Public Health. 2015. https://doi.org/10.1155/2015/971506.

13. Ndidi EP, Oseremen IG. Reasons given by pregnant women for late initiation of antenatal care in the niger delta. Nigeria. Ghana Med J. 2010:44(2):47-51.

14. Onoh R, Umeora O, Agwu U, Ezegwui H, Ezeonu P, Onyebuchi A. Pattern and determinants of antenatal booking at Abakaliki southeast Nigeria. Ann Med Health Sci Res. 2013;2(2):169-75.

15. Banda I, Michelo C, Hazemba A. Factors associated with late antenatal care attendance in selected rural and urban communities of the copperbelt province of Zambia. Med J Zambia. 2014;39(3):29-36.

16. Adekanle DA, Isawumi Al. Late antenatal care booking and its predictors among pregnant women in South Western Nigeria. Online J Health Allied Sci. 2008;7(1):4.

17. Tekelab T, Berhanu B. Factors associated with late initiation of antenatal care among pregnant women attending antenatal clinic at Public Health Centers in Kembata Tembaro Zone, Southern Ethiopia. Sci Technol Arts Res J. 2014;3(1):108-15.

18. Gudayu TW, Woldeyohannes SM, Abdo AA. Timing and factors associated with first antenatal care booking among pregnant mothers in Gondar Town; North West Ethiopia. BMC Pregnancy Childbirth. 2014;14(1):287.

19. International CSAAI. Demographic E. Health survey report. 2016.

20. Belayneh T, Adefris M, Andargie G. Previous early antenatal service utilization improves timely booking: cross-sectional study at university of Gondar Hospital, northwest Ethiopia. J Pregnancy. 2014. https://doi. org/10.1155/2014/132494.

21. Fantahun M, Kedir A, Mulu A, Adugna D, Meressa D, Muna E. Assessment of antenatal care services in a rural training health center in Northwest Ethiopia. Ethiop J Health Dev. 2000;14(2):155-60.

22. Gross K, Alba S, Glass TR, Schellenberg JA, Obrist B. Timing of antenatal care for adolescent and adult pregnant women in south-eastern Tanzania. BMC Pregnancy Childbirth. 2012;12(1):1.

23. Exavery A, Kanté AM, Hingora A, Mbaruku G, Pemba S, Phillips JF. How mistimed and unwanted pregnancies affect timing of antenatal care initiation in three districts in Tanzania. BMC Pregnancy Childbirth. 2013;13(1):35.

24. Lerebo W, Kidanu A, Tsadik M. Magnitude and associated factors of late booking for antenatal care in Public Health Centers of Adigrat Town, Tigray, Ethiopia. Clin Mother Child Health. 2015;12(171):2.

25. Okunlola M, Ayinde O, Owonikoko K, Omigbodun A. Factors influencing gestational age at antenatal booking at the University College Hospital, Ibadan, Nigeria. J Obstet Gynaecol. 2006;26(3):195-7.

26. Soontornprakasit P, Mongkolchati A, Chompikul J. Factors associated with time to start antenatal care within 12 weeks gestational age among mothers in Mahasarakham province, Thailand. J Public Health Dev. 2016;14(1):21-36.

27. Lerebo W, Kidanu A, Tsadik M. Magnitude and associated factors of late booking for antenatal care in Public Health Centers of Adigrat Town, Tigray, Ethiopia. Clin Mother Child Health. 2015;12:(1).

28. Bbaale E. Factors influencing timing and frequency of antenatal care in Uganda. Australas Med J. 2011;4(8):431.

29. Tran TK, Gottvall K, Nguyen HD, Ascher H, Petzold M. Factors associated with antenatal care adequacy in rural and urban contexts-results from two health and demographic surveillance sites in Vietnam. BMC Health Serv Res. 2012;12(1):1. 
30. Jewkes RK, Abrahams N, Mvo Z. Study of health care seeking practices of pregnant women in Cape Town. Report four, summary of findings, conclusions and policy action. 1998.
31. Mugo NS, Dibley MJ, Agho KE. Prevalence and risk factors for non-use of antenatal care visits: analysis of the 2010 South Sudan household survey. BMC Pregnancy Childbirth. 2015;15(1):1.
Ready to submit your research? Choose BMC and benefit from:

- fast, convenient online submission

- thorough peer review by experienced researchers in your field

- rapid publication on acceptance

- support for research data, including large and complex data types

- gold Open Access which fosters wider collaboration and increased citations

- maximum visibility for your research: over $100 \mathrm{M}$ website views per year

At BMC, research is always in progress.

Learn more biomedcentral.com/submissions 